\title{
Supporting Information \\ Structural Phase Transformation in Amorphous \\ Molybdenum Disulfide During Friction
}

\author{
Yanbin Shi ${ }^{\mathrm{a}, \mathrm{b}}$, Jibin $\mathrm{Pu}^{\mathrm{a},{ }^{*}}$, Liping Wang ${ }^{\mathrm{a}}$
}

a. Key Laboratory of Marine Materials and Related Technologies, Zhejiang Key Laboratory of Marine Materials and Protective Technologies, Ningbo Institute of Materials Technology and Engineering, Chinese Academy of Sciences, Ningbo 315201, China

b. University of Chinese Academy of Sciences, Beijing 100049, China 
*Corresponding authors

Prof. Jibin Pu. E-mail:pujibin@nimte.ac.cn. Tel.: + 86-057-486690267. Fax: +86-057-486685159

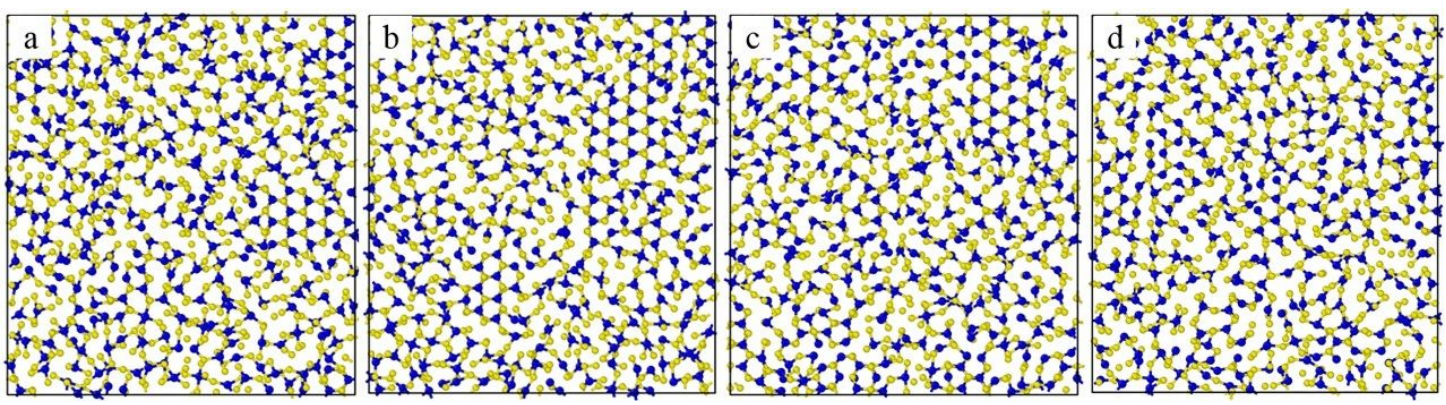

Figure S1. Snapshots taken from the MD trajectory of the systems in the simulation of 25 ps at different temperatures (a:1000 K, b:2000 K, c:3000 K and d:4000 K). All MD trajectories are calculated with load equal to $1.60 \mathrm{nN}$. Molybdenum and sulfur atoms are shown in blue and yellow, respectively. 


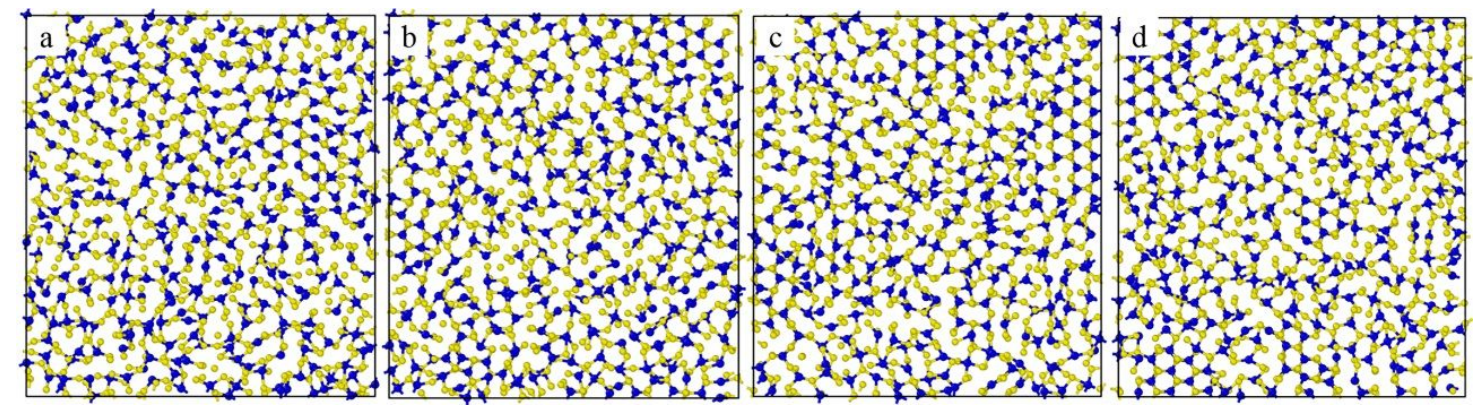

Figure S2. Snapshots taken from the MD trajectory of the systems in the simulation of $25 \mathrm{ps}$ at different load (a: $1.28 \mathrm{nN}, \mathrm{b}: 1.44 \mathrm{nN}$, c: $1.76 \mathrm{nN}$ and $\mathrm{d}: 1.92 \mathrm{nN}$ ). All MD trajectories are calculated with temperature equal to $3000 \mathrm{~K}$.
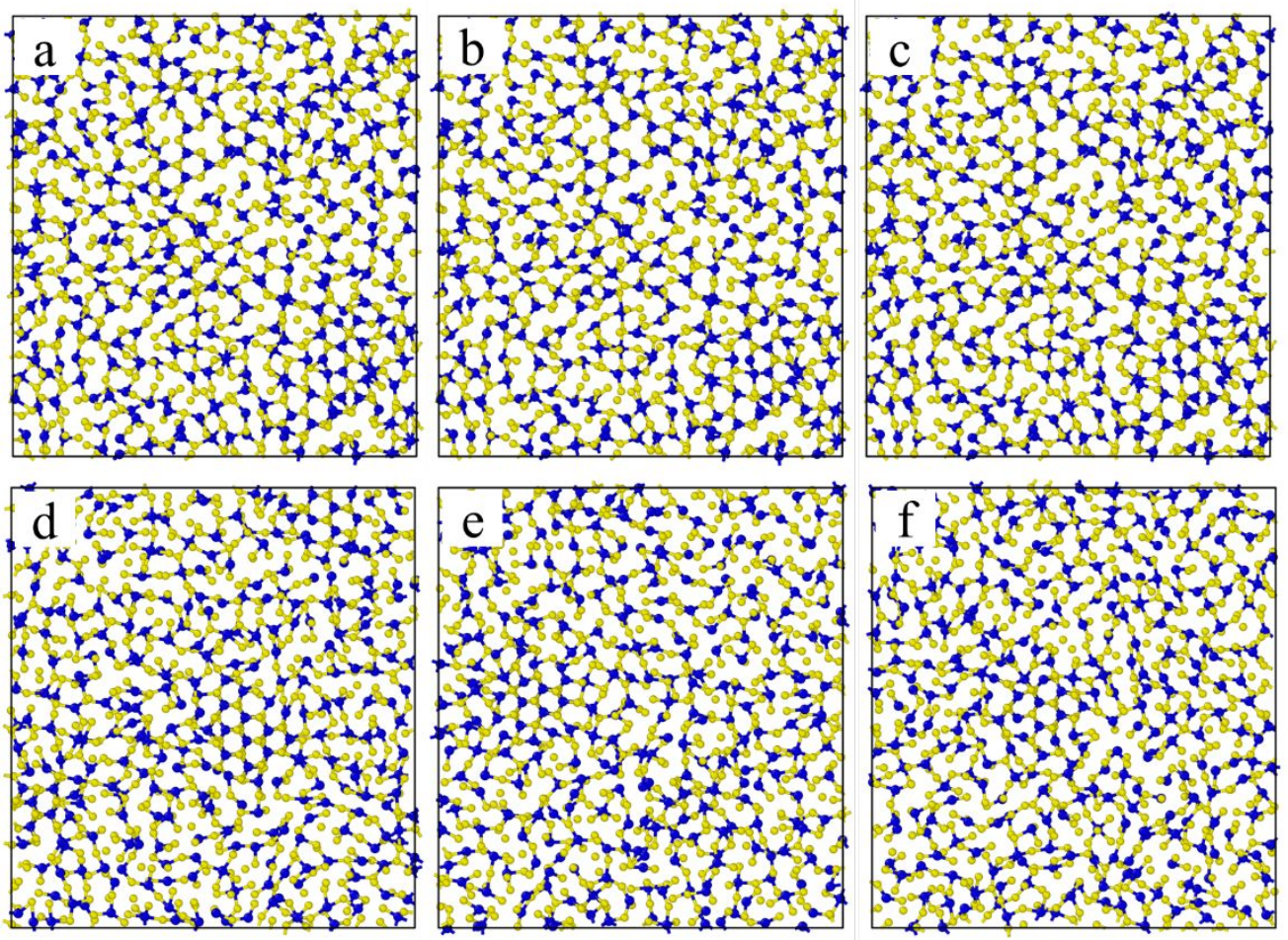

Figure S3. Snapshots taken from the MD trajectory of the systems (a-c: 
$1000 \mathrm{~K}-0 \mathrm{~m} / \mathrm{s}$; d-f: $1000 \mathrm{~K}-5 \mathrm{~m} / \mathrm{s}$ ) in the simulation at different time (From left to right: $500 \mathrm{ps}, 1 \mathrm{~ns}$ and $2 \mathrm{~ns}$ ).
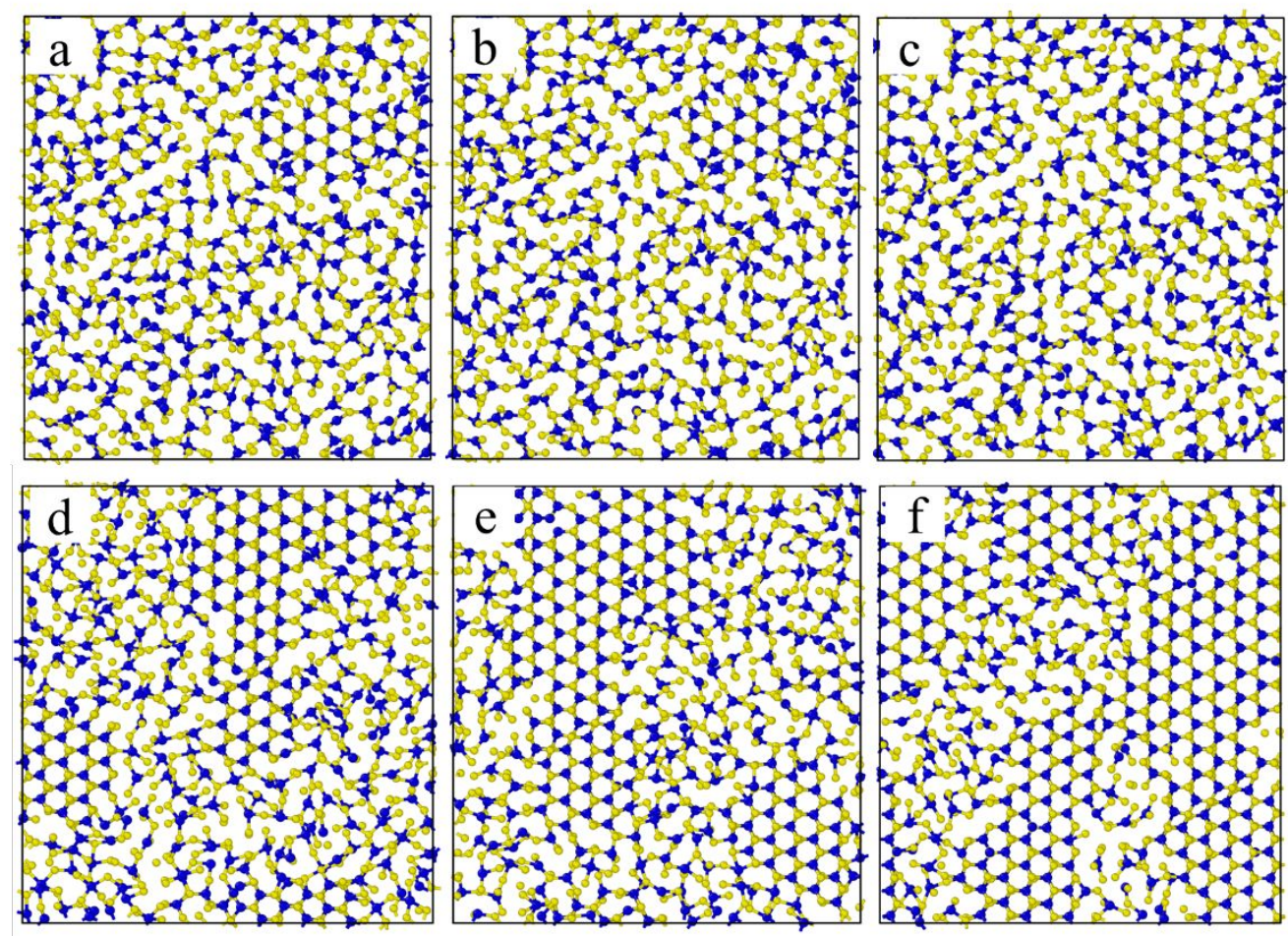

Figure S4. Snapshots taken from the MD trajectory of the systems (a-c:

$2000 \mathrm{~K}-0 \mathrm{~m} / \mathrm{s}$; d-f: $2000 \mathrm{~K}-5 \mathrm{~m} / \mathrm{s}$ ) in the simulation at different time (From left to right: $500 \mathrm{ps}, 1 \mathrm{~ns}$ and $2 \mathrm{~ns}$ ). 

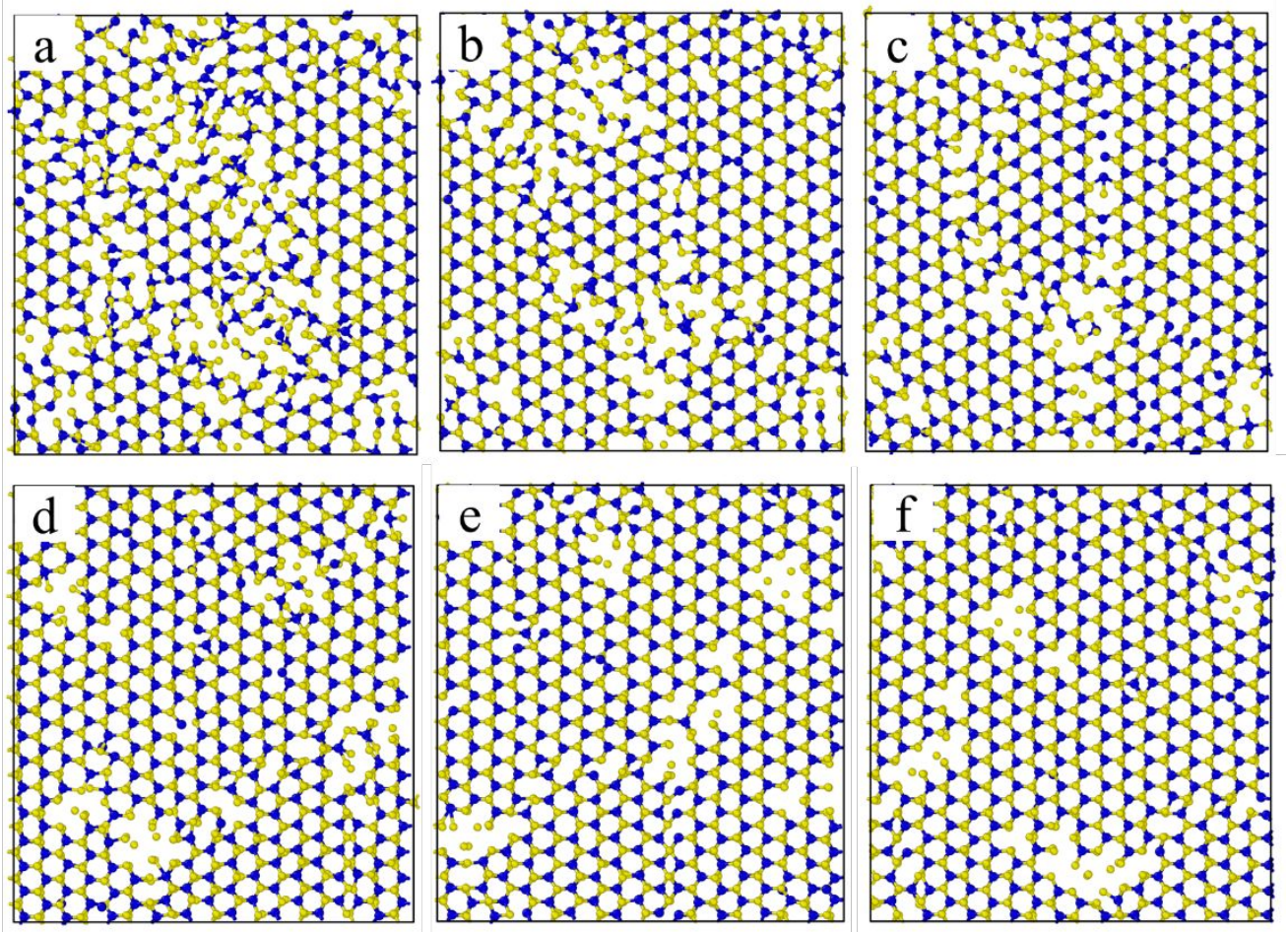

Figure S5. Snapshots taken from the MD trajectory of the systems (a-c: $3000 \mathrm{~K}-0 \mathrm{~m} / \mathrm{s}$; d-f: $3000 \mathrm{~K}-5 \mathrm{~m} / \mathrm{s}$ ) in the simulation at different time (From left to right: $500 \mathrm{ps}, 1 \mathrm{~ns}$ and 2ns). 

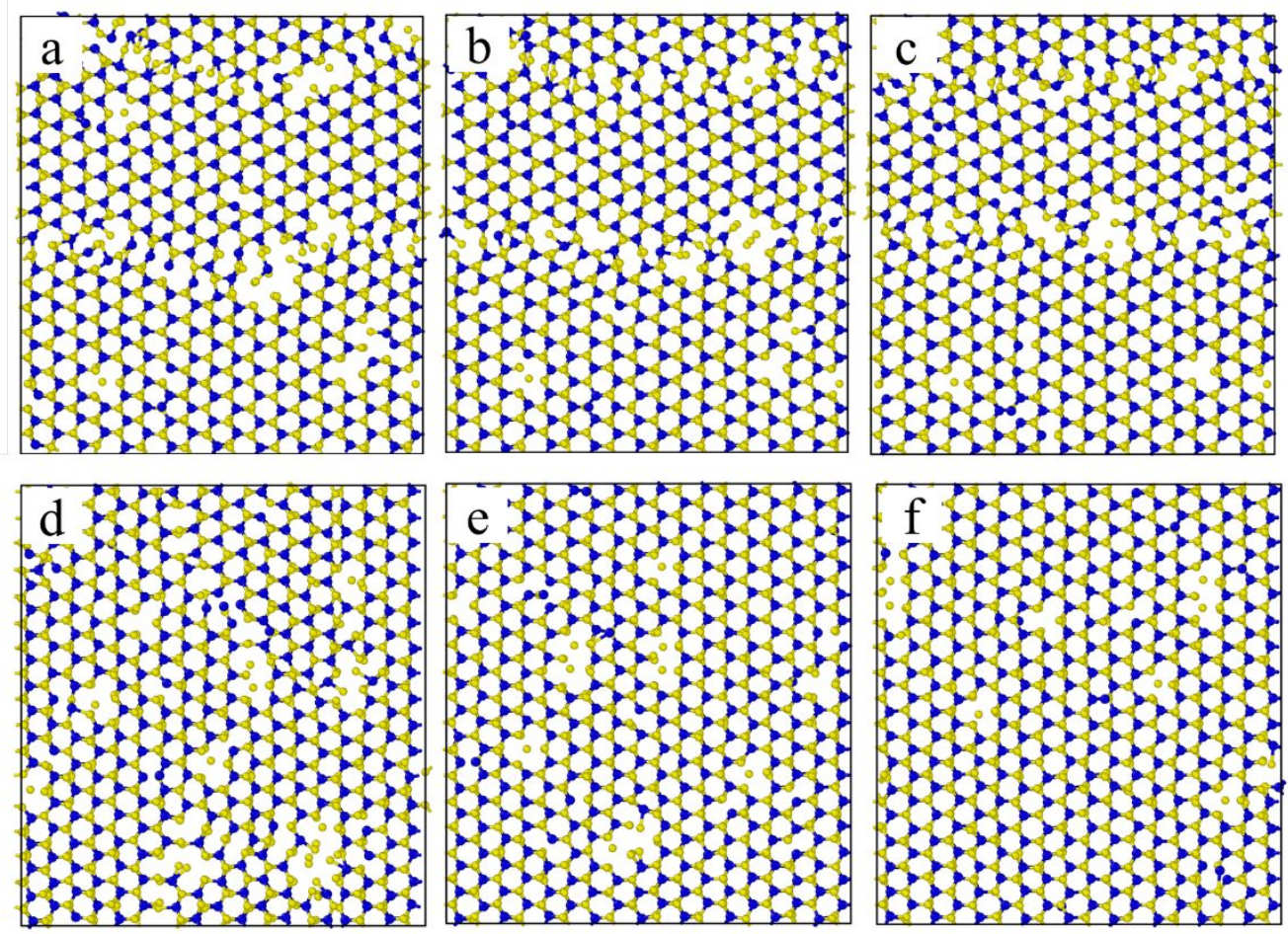

Figure S6. Snapshots taken from the MD trajectory of the systems (a-c: $4000 \mathrm{~K}-0 \mathrm{~m} / \mathrm{s}$; d-f: $4000 \mathrm{~K}-5 \mathrm{~m} / \mathrm{s}$ ) in the simulation at different time (From left to right: $500 \mathrm{ps}, 1 \mathrm{~ns}$ and 2ns). 


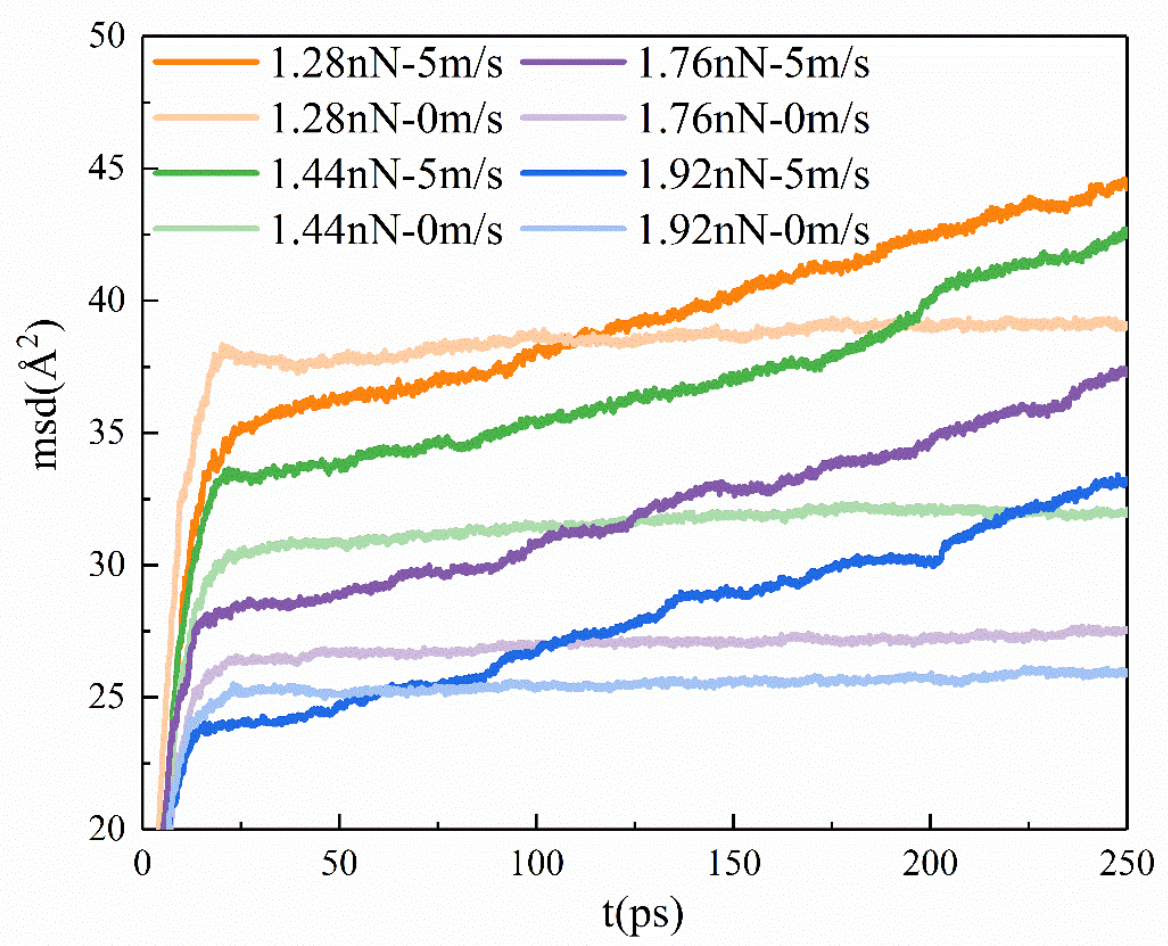

Figure S7. Mean square displacement curves of atoms in amorphous layers at a temperature equal to $3000 \mathrm{~K}$, and at different loading force (1.28 nN/atom, $1.44 \mathrm{nN} /$ atom, $1.60 \mathrm{nN} /$ atom, $1.76 \mathrm{nN} /$ atom and 1.92 nN/atom). 


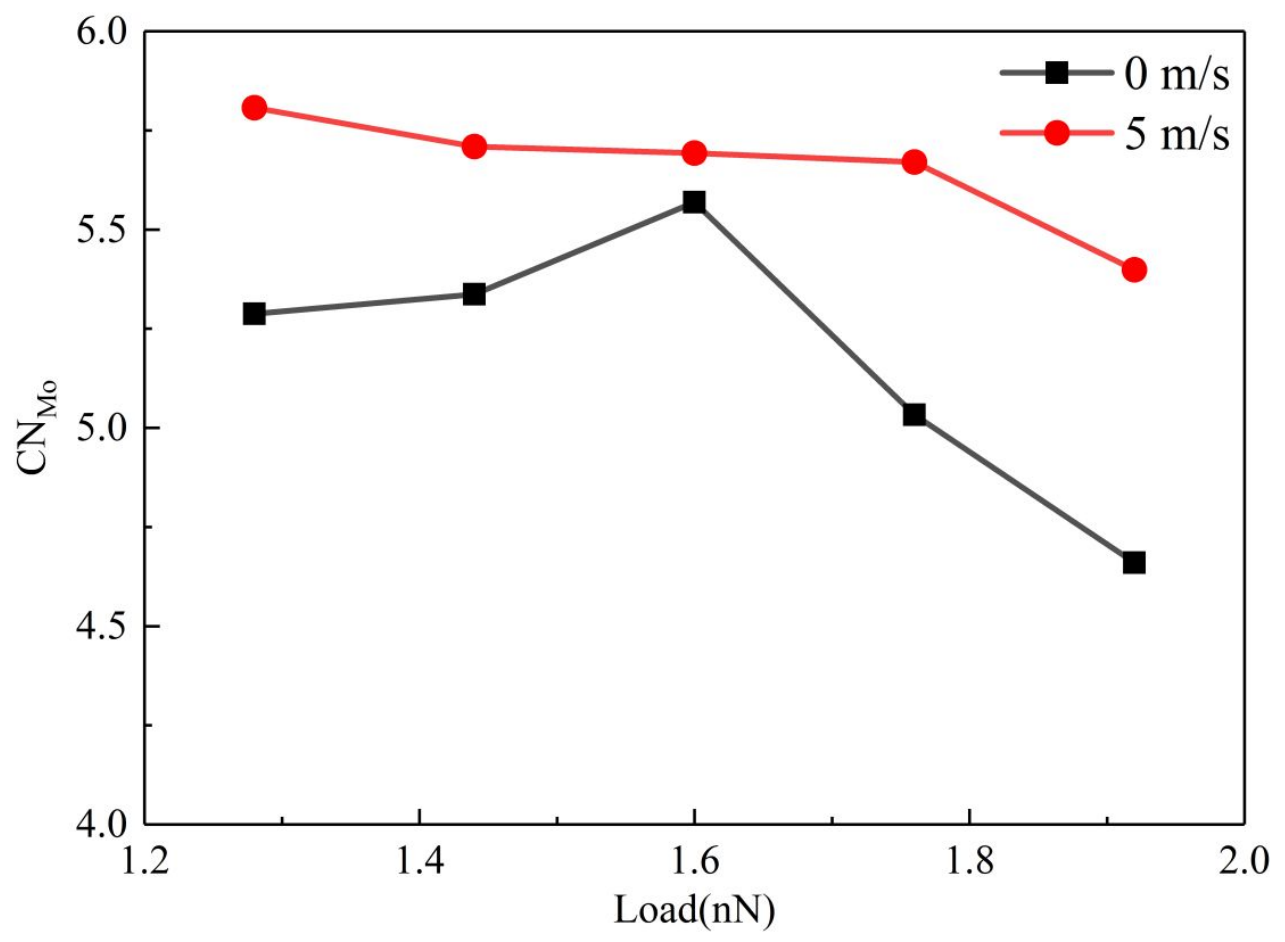

Figure S8. Coordination number of Mo in the amorphous layer at 2 ns, with the temperature equal to $3000 \mathrm{~K}$. 

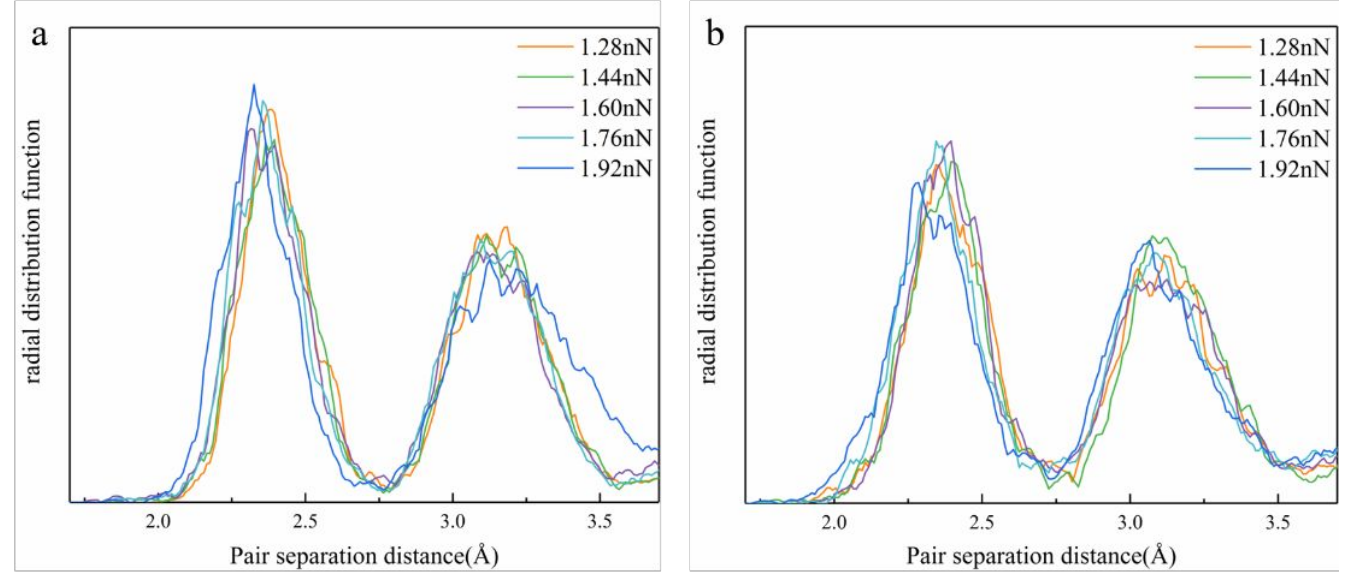

\begin{tabular}{c|c|c|c|c|c|c|c|c|c|c}
$\mathrm{C} \quad$ Speed $(\mathrm{m} / \mathrm{s})$ & \multicolumn{6}{|c|}{$\mathrm{V}=5 \mathrm{~m} / \mathrm{s}$} & \multicolumn{6}{c}{$\mathrm{V}=0 \mathrm{~m} / \mathrm{s}$} \\
\hline Load $(\mathrm{nN})$ & 1.28 & 1.44 & 1.60 & 1.76 & 1.92 & 1.28 & 1.44 & 1.60 & 1.76 & 1.92 \\
\hline $\begin{array}{c}\text { Min distance } \\
\text { Mo-S }(\AA) \\
\begin{array}{c}\text { Max distance } \\
\text { Mo-S }(\AA)\end{array}\end{array}$ & 2.035 & 1.965 & 1.935 & 1.925 & 1.985 & 1.945 & 1.985 & 1.915 & 1.995 & 1.915 \\
& 2.765 & 2.775 & 2.805 & 2.825 & 2.785 & 2.745 & 2.845 & 2.715 & 2.645 & 2.725
\end{tabular}

Figure S9. The radial distribution functions of the crystal structure at different loads (1.28 nN, $1.44 \mathrm{nN}, 1.60 \mathrm{nN}, 1.76 \mathrm{nN}$ and $1.92 \mathrm{nN})$, with the sliding speed equal to $5 \mathrm{~m} / \mathrm{s}$ (a) and $0 \mathrm{~m} / \mathrm{s}(\mathrm{b})$ 